\title{
A Case-Based Approach to Colorectal Cancer Detection
}

\author{
Pedro Morgado $^{1}$, Henrique Vicente ${ }^{1,2}$, António Abelha ${ }^{1}$, José Machado ${ }^{1}$, \\ João Neves ${ }^{3}$, and José Neves ${ }^{1(\varpi)}$ \\ ${ }^{1}$ Centro Algoritmi, Universidade do Minho, Braga, Portugal \\ pedrommcs@hotmail.com, \{abelha, jmac, jneves\}@di.uminho.pt \\ 2 Departamento de Química, Escola de Ciências e Tecnologia, Universidade de Évora, \\ Évora, Portugal \\ hvicente@uevora.pt \\ ${ }^{3}$ Mediclinic Arabian Ranches, PO Box 282602, Dubai, United Arab Emirates \\ joaocpneves@gmail.com
}

\begin{abstract}
Colorectal cancer is one of the most common malignancies in developed countries. Although it is not well known what causes this type of cancer, studies have showed that there are certain risk factors associated that may increase the likelihood of developing such malignancy. These factors comprise, among others, individual's age, lifestyle habits, personal disease history, and genetic syndromes. Despite its high mortality, colorectal cancer may be prevented with an early diagnosis. Thus, this work aims at the development of Artificial Intelligence based decision support system to assess the risk of developing colorectal cancer. The framework is built on top of a Logic Programming approach to Knowledge Representation and Reasoning, complemented with a Case-based approach to computing that caters for the handling of incomplete, unknown, or even self-contradictory data, information or knowledge.
\end{abstract}

Keywords: Colorectal cancer $\cdot$ Knowledge representation and reasoning $\cdot$ Logic programming $\cdot$ Case-based reasoning $\cdot$ Decision support systems 